\title{
Collaborative Mobile Learning with Smartphones in Higher Education
}

\author{
https://doi.org/10.3991/ijim.v14i21.18461
}

\author{
Korlan Zhampeissova $(\bowtie)$ \\ Abai Kazakh National Pedagogical University, Almaty, Kazakhstan \\ zhampeissovako@rambler.ru / khorlan_17@mail.ru \\ Irina Kosareva \\ Moscow State Automobile and Road Construction Technical University, \\ Moscow, Russia \\ Uliana Borisova \\ North-Eastern Federal University (NEFU), Yakutsk, Russia
}

\begin{abstract}
The advantages of mobile learning and the possibility of universal access to educational materials have a downside in the form of a possible lack of communication between the student, his/her teachers, and course mates. In this context, collaborative teaching methods can be applied to support learners in solving educational challenges. The objective of this work was to analyze the effectiveness of collaborative approaches in mobile learning. The research methods included two stages: an experiment on the introduction of collaborative mobile learning into the educational process and an online sociological survey. The use of the questionnaire method resulted from the need to collect quantitative data and analyze the effectiveness of training by determining the shares of respondents with positive and negative opinions toward $\mathrm{m}$-learning. The examination was conducted in 2020 among 190 undergraduate sociology students studying at three universities of the Russian Federation (Moscow State Pedagogical University, M.K. Ammosov North-Eastern Federal University, and Tyumen State University), as well as among 76 undergraduate students of the direction "Education" studying at Abai Kazakh National Pedagogical University. The main practical result of this experiment was the introduction of mobile technologies in the previously used e-learning models and learning management systems of the considered educational institutions. The collaborative mobile environment was based on the principles of communication and cooperation of users, mutual learning, and teacher coordination of students' actions. The study confirmed that collaborative mobile learning could be flexibly transited from blended to distance learning models and vice versa. The analysis of the survey outcomes proved the validity of eight proposed hypotheses, both in terms of mobile learning impact on the quality of education and the influence of the collaborative environment on the development of students' competencies. The practical significance of research findings is in the fact that they allow the effective implementation of collaborative mobile learning technologies to form students' professional competencies.
\end{abstract}

Keywords - Collaborative learning, distance learning, e-learning, mobile learning, online learning, smartphone 


\section{Introduction}

Electronic learning (e-learning), as well as distance learning (d-learning) and mobile learning (m-learning), continue to be among the main trends in modern education [1]. The fundamental difference of m-learning from other training modes lies in the use of individual devices (smartphones or tablets) to access educational content at any time [2]. Nowadays, smartphones are referred to as the most popular gadgets in the world. Mobile accounts for approximately half of the web traffic worldwide [3].

For developing countries, m-learning remains an excellent opportunity for more expanded and cheaper delivery of educational services [4]. In the case of optimal organization of communication between teachers and students, m-learning promotes the development of better student-teacher cooperation and contributes to the full involvement of learners in the educational process [5]. At the same time, to provide a full-fledged education supported by mobile technologies, it is necessary to have an appropriate environment and communication culture [6].

As a rule, in m-learning, the student has access not only to the content of a particular educational platform but also to various Internet resources. Thus, the materials of the Learning Management System (LMS) and Massive Open Online Course (MOOC) in the m-learning context should be supplemented by various informational resources, rather than created from scratch [7]. For Generation Z, as the most widely involved in the education process, the use of smartphones and mobile applications is usual [8]. Therefore, for such students, m-learning can become an accessible environment that ensures constant presence and full access to training materials. In this case, interactivity, flexibility, and friendliness of m-learning methods are crucial [9]. The disadvantages of mobile devices affecting m-learning organization include relatively low processing power, small screen size, and fast battery discharge during continuous operation [10]. M-learning opportunities are widely influenced by the degree of development of the local technological infrastructure and the quality of the available communication channels. Nevertheless, in the Russian Federation and Kazakhstan, as well as in most other countries, mobile technologies are being actively introduced into education, which creates the need for a comprehensive study of this phenomenon.

The practical significance of the study results is that they allow the effective implementation of collaborative m-learning (CML) technologies for the formation of students' competencies.

The scientific novelty of this research lies in the fact that it analyzes the effectiveness of collaborative mobile learning (CML) implementation in the formation of students' competencies. Furthermore, the paper reveals new experimental data that confirm the positive influence of m-learning activities.

\section{$2 \quad$ Literature Review}

A specific feature of m-learning is the support for an extracurricular education model that does not require traditional in-class study [11]. M-learning can be applied everywhere where one can connect to the Internet. Apart from this, m-learning is one 
more way to benefit from the everyday use of smartphones [12]. The statistics show that most of the daily smartphone usage time is spent on social networks. According to the global report Digital 2020, $89 \%$ of those connected to the Internet are active social media users. Thus, the use of social networks, both in terms of entertainment and for research tasks, is a characteristic feature of m-learning [13]. This approach is especially crucial for humanities students, who master professions connected with human-human interaction [14].

Mobile platforms and social networks provide a large amount of video and audio material that can also be used for educational purposes in an independent asynchronous mode [15]. An important aspect of m-learning is support for both blended and fully distance training models, which allows, if necessary, a flexible transition from one model to another [16].

In the framework of this study, it is necessary to discuss teaching methods that have gained a new impetus for development after the introduction of e-learning. Such methods and techniques are complementary and, as a rule, are implemented in a complex within one or another educational model [17]. Collaborative or cooperative learning consists of group partnerships between students that help to complete learning tasks (in some cases, a teacher may also be involved in the study group) [18]. Various kinds of social and communication platforms complement and support m-learning technologies aimed at developing students' cooperation skills in the virtual space [19].

Problem-based learning (PBL) is a natural environment for collaborative education, where students undertake a project to solve real challenges [20]. PBL is often associated with a broader range of problem-based methods, which are more directly centered at the learning process based on transformational activities than at obtaining any tangible products [21]. The organization of a network project repository allows one to access it using mobile technologies. At the same time, university business incubators directed at developing innovation within the entrepreneurial university model remain a suitable environment for supporting student projects [22].

Active teaching methods are oriented at the independent formation of students' personal and professional competencies during the educational process [23]. The modern implementation of this principle is achieved by applying various interactive mobile teaching technologies such as virtual and augmented reality. In this case, the dialogue occurs in the form of human-machine interaction with the teacher, fellow students, or components of the learning environment. One more interactive method that deserves to be discussed is gamification. It uses mobile applications to implement game elements that support the acquisition of desired knowledge and skills [24].

Individual student-centered instruction [25] also harmoniously fits the m-learning concept since the accessibility of materials and learning environment contributes to the formation of personal learning trajectories. Student-centered training can be complemented by a self-regulatory approach to education focused on the targeted development of particular knowledge, skills, or personal qualities. In both cases, a learner, under the guidance of a teacher, thinks over the education process and its stages [26].

The development of e-learning and m-learning practices provided a new stimulus to the introduction of collaborative methods in education. Consequently, most educa- 
tional technologies and methods above can be successfully integrated with the collaborative learning model [27].

The analysis of the ways of introducing m-learning into the educational process confirms that collaborative education is one of the most useful mobile learning methods. Considering that collaborative training allows the implementation of other modern methodologies, it seems relevant to investigate and review empirical data on CML. However, given that well-known works have mainly investigated the general $\mathrm{m}$-learning aspects, regardless of their implementation methods, the present research intends to partially fill this gap.

\subsection{Problem statement}

The basis for the application of CML is the creation and support of a collaborative mobile environment, built on the principles of user communication, cooperation, mutual education, and coordination of learner's actions by the teacher. The examination of these principles' effectiveness created the foundation for the development of the following research hypotheses:

- H1 - CML ensures student satisfaction with the educational process.

- H2 - CML motivates to make more efforts to acquire new knowledge and skills.

- H3 - CML guarantees that students understand the content of the proposed practical tasks.

- H4 - CML ensures the development of students' communication skills.

- H5 - CML promotes mutual learning through the exchange of ideas and knowledge.

- H6 - For the successful CML application, regular online support from teachers and fellow students is required.

- $\mathbf{H 7}$ - Teacher's coordination of work in the course of CML contributes to the students' feeling of the educator's involvement.

- H8 - Teacher's coordination of work in the course of CML contributes to the students' sense of fairness in the knowledge assessment.

The objective of this work was to analyze the effectiveness of collaborative approaches in m-learning. In order to perform a comprehensive analysis, the following tasks were set:

- Introduce m-learning in the educational process and create a collaborative environment for teaching sociological and pedagogical disciplines.

- Develop a questionnaire for a sociological survey to evaluate the effectiveness of collaborative approaches in m-learning.

- Survey students and teachers of four higher educational institutions where CML was introduced.

- Analyze research results to test the study hypotheses. 


\section{$3 \quad$ Materials and Methods}

\subsection{Research design and sample}

The research methods included an experiment on the implementation of CML into the educational process and an online sociological survey. The use of the survey method to collect quantitative data and analyze the training effectiveness can be explained by the fact that it was necessary to determine the share of students with positive and negative opinions toward their experience in m-learning.

The experimental study was carried out in 2020 among undergraduate sociology students of three Russian universities and students of the direction "Education" in one Kazakhstan higher educational institution. The examination process involved learners from Moscow State Pedagogical University (MSPU), M. K. Ammosov North-Eastern Federal University (NEFU), Tyumen State University (UTMN), and Abai Kazakh National Pedagogical University (KNPU). These institutions had already tested a blended learning system in the considered study directions and planned to develop $\mathrm{m}$ learning methods for students and teachers. The present research was aimed at introducing m-learning technologies during one academic semester with subsequent surveying of the involved study participants. Table 1 presents data on the sample population. The uneven distribution of students can be explained by the differences in the enrollment of applicants in the examined educational directions.

Table 1. Sample Population

\begin{tabular}{|l|c|c|c|c|c|c|}
\hline & MSPU & NEFU & UTMN & KNPU & Average & Total \\
\hline Number of respondents & 93 & 39 & 58 & 76 & 66 & 266 \\
\hline Average age & 20.4 & 21.2 & 21.4 & 21.4 & 21.1 & - \\
\hline Men, number & 32 & 14 & 24 & 36 & 26 & 106 \\
\hline Women, number & 61 & 25 & 34 & 40 & 40 & 160 \\
\hline Men, \% & $34 \%$ & $36 \%$ & $41 \%$ & $47 \%$ & - & $39.8 \%$ \\
\hline Women, \% & $66 \%$ & $64 \%$ & $59 \%$ & $53 \%$ & - & $60.2 \%$ \\
\hline Number of processed questionnaires & 89 & 38 & 55 & 74 & 64 & 256 \\
\hline
\end{tabular}

\subsection{Experiment and survey}

The experiment was carried out in the course of the study of the subject "Methodology and methods of sociological research," included in the main block of disciplines for training bachelors in sociology and the subject "National upbringing" studied by those seeking bachelor's degree in education. For these study courses, online technologies were already introduced into the training process in the MOOC format and were used according to the blended learning model. Consequently, teachers already had sufficient experience in using e-learning methods. At the end of 2019, before the start of the new semester and before the experiment began, it was decided to supplement the educational process with mobile technologies.

The offered m-learning content included links to self-paced YouTube videos; instructions and links to access mobile applications and conduct online sociological and 
educational research (SurveyMonkey and Google Forms); components of the collaborative learning environment implemented in the LMS (forum, training assignments and a platform for posting, commenting and revising them). The primary purpose of the collaborative mobile environment was to work in groups (usually two or more people) to complete practical tasks. The main goal of such training was to master the methodology and tools for carrying out sociological and educational research online [28]. Thus, the practical exercises included the analysis of services for conducting research on the Internet, the organization of research process in social networks, and the use of online applications for collecting and processing results.

The access to the forum was provided for all participants of the educational course. Students' questions concerning the working process could be addressed both to the teacher (more complex ones, as a rule, related to the study design) and to fellow students (mainly concerning the technical issues). By forum discussions, learners had the opportunity to observe the progress of other teams. Teachers were required to answer students' questions every day, contributing to the feeling of almost $24 / 7$ online support.

During the study semester, each respondent conducted several online researchers (3 or 4, depending on the program and specialization of a particular university). The work planning and distribution of tasks within the groups were conducted by students independently.

At the end of the semester, all students in the sample were proposed to fill out the questionnaire with two thematic sections. The first included three questions that were supposed to outline the impact of m-learning on the quality of the educational process. The second section comprised questions devoted to the possibilities of collaborative methods in terms of the development of communication, cooperation, mutual learning, and teacher coordination of students' actions. The questions of the survey were formulated in the form of statements, to which respondents had to give one of three answers: "Agree," "Disagree," or "Neither agree nor disagree."

\subsection{Data analysis}

The collection of respondents' answers was carried out online through Google Forms. Data were processed using Microsoft Excel spreadsheets and analyzed by calculating the frequency of occurrence of each of the answer options ("Agree," "Disagree," or "Neither agree nor disagree").

\subsection{Statistical processing}

The main study variable was the percentage of students for each of the three proposed answers. The mean values were determined for the whole sample and not as the arithmetic mean for three universities. The final results are presented in Table 2 (Results section).

The study involved all second-year undergraduate students of MSPU, NEFU, and UTMN as well as first-year undergraduate students of KNPU. The research population included 266 respondents. At the same time, only 256 completed questionnaires 
were accepted for processing. Through the formula for the calculation of the standard deviation, it was found that the statistical sampling error does not exceed $1.5 \%$, with a probability of 0.95 .

\subsection{Research limitations}

The present study covered students of only one academic year of each educational institution under consideration. What is more, the obtained data were based on students' self-esteem, so that, to a certain extent, they can be considered subjective. Such self-assessment results could be influenced by students' individual qualities and interpersonal relationships developed during the formation of working groups and collaborated learning. Besides, in the created groups, quite obvious heterogeneities were noted in terms of students' experience and motivation. The participants' impressions from the use of m-learning technologies largely depended on teachers' personal characteristics and methods to organize communication.

Nevertheless, the objectivity of the obtained empirical data can be justified because the research involved only those educators who were qualified users of m-learning technologies. Furthermore, the teachers were motivated to get the best results from the introduction of mobile education. This study revealed similar survey outcomes in four universities of different regions of the Russian Federation and Kazakhstan with a unique academic environment. Therefore, the collected data contributed to important conclusions on how to increase CML's effectiveness based on communication, mutual learning, and coordination of the educational process.

\subsection{Ethical issues}

One of the priority tasks of the study was to ensure the maximum response from the students. To achieve this goal and, at the same time, ensure the respondents' anonymity, the survey questions did not address the personal life aspects of the enrolled students, and data collection was carried out using Google Forms.

Before the start of the experiment, participants were informed about the purpose of the study and the further publication of its results. When discussing the research plan, no negative reaction was observed among the involved. Study participants were guaranteed the absence of any adverse consequences in case of refusal to complete the questionnaire. The survey method excluded covert observation of respondents. The questionnaires were not tied to respondent identifiers. Other persons who did not participate in this project had no access to the survey results or related information. Moreover, at the end of data processing, the completed questionnaires were deleted. Given this, it can be argued that the research participants' rights and interests were respected.

\section{$4 \quad$ Results}

The results of the conducted survey are presented in Table 2 . 
Table 2. Survey Results

\begin{tabular}{|c|c|c|c|c|c|}
\hline & MSPU & NEFU & UTMN & KNPU & Average \\
\hline \multicolumn{6}{|c|}{$\begin{array}{l}\text { In general, I am satisfied with the way m- } \\
\text { learning was organized }\end{array}$} \\
\hline Agree & $87.6 \%$ & $92.1 \%$ & $85.5 \%$ & $90.5 \%$ & $88.7 \%$ \\
\hline Neither agree nor disagree & $9 \%$ & $2.6 \%$ & $3.6 \%$ & $5.5 \%$ & $5.9 \%$ \\
\hline Disagree & $3.4 \%$ & $5.3 \%$ & $10.9 \%$ & $4 \%$ & $5.4 \%$ \\
\hline \multicolumn{6}{|c|}{$\begin{array}{l}\text { M-learning motivates me to put more effort } \\
\text { into acquiring new knowledge and skills }\end{array}$} \\
\hline Agree & $65.2 \%$ & $76.3 \%$ & $72.7 \%$ & $70 \%$ & $69.9 \%$ \\
\hline Neither agree nor disagree & $25.8 \%$ & $13.2 \%$ & $14.5 \%$ & $15 \%$ & $18.3 \%$ \\
\hline Disagree & $9 \%$ & $10.5 \%$ & $12.7 \%$ & $15 \%$ & $11.7 \%$ \\
\hline \multicolumn{6}{|c|}{ I understand the proposed practical tasks } \\
\hline Agree & $83.1 \%$ & $81.6 \%$ & $80 \%$ & $82.4 \%$ & $82 \%$ \\
\hline Neither agree nor disagree & $3.4 \%$ & $7.9 \%$ & $3.6 \%$ & $5.4 \%$ & $4.7 \%$ \\
\hline Disagree & $13.5 \%$ & $10.5 \%$ & $16.4 \%$ & $12.2 \%$ & $13.3 \%$ \\
\hline \multicolumn{6}{|c|}{$\begin{array}{l}\text { My communication skills improved after m- } \\
\text { learning practices }\end{array}$} \\
\hline Agree & $69.7 \%$ & $71.1 \%$ & $72.7 \%$ & $71.6 \%$ & $71.1 \%$ \\
\hline Neither agree nor disagree & $19.1 \%$ & $10.5 \%$ & $7.3 \%$ & $10.8 \%$ & $12.9 \%$ \\
\hline Disagree & $11.2 \%$ & $18.4 \%$ & $20 \%$ & $17.6 \%$ & $16 \%$ \\
\hline \multicolumn{6}{|c|}{ My groupmates shared ideas and knowledge } \\
\hline Agree & $65.2 \%$ & $63.2 \%$ & $74.5 \%$ & $68.9 \%$ & $68 \%$ \\
\hline Neither agree nor disagree & $22.5 \%$ & $18.4 \%$ & $9.1 \%$ & $17.6 \%$ & $19.1 \%$ \\
\hline Disagree & $12.4 \%$ & $18.4 \%$ & $16.4 \%$ & $13.5 \%$ & $12.9 \%$ \\
\hline \multicolumn{6}{|c|}{$\begin{array}{l}\text { Online support from teachers and course mates } \\
\text { helped me to complete the assignments suc- } \\
\text { cessfully }\end{array}$} \\
\hline Agree & $64 \%$ & $60.5 \%$ & $70.9 \%$ & $70.3 \%$ & $66.8 \%$ \\
\hline Neither agree nor disagree & $21.3 \%$ & $18.4 \%$ & $10.9 \%$ & $16.2 \%$ & $17.2 \%$ \\
\hline Disagree & $14.6 \%$ & $21.1 \%$ & $18.2 \%$ & $13.5 \%$ & $16 \%$ \\
\hline \multicolumn{6}{|c|}{$\begin{array}{l}\text { Teachers made a significant contribution to the } \\
\text { study process and work results of my group }\end{array}$} \\
\hline Agree & $70.8 \%$ & $63.2 \%$ & $69.1 \%$ & $66.2 \%$ & $68 \%$ \\
\hline Neither agree nor disagree & $18 \%$ & $21.1 \%$ & $9.1 \%$ & $23 \%$ & $17.9 \%$ \\
\hline Disagree & $11.2 \%$ & $15.8 \%$ & $21.8 \%$ & $10.8 \%$ & $14.1 \%$ \\
\hline \multicolumn{6}{|c|}{$\begin{array}{l}\text { My training outcomes within m-learning were } \\
\text { adequately assessed by the teacher }\end{array}$} \\
\hline Agree & $71.9 \%$ & $76.3 \%$ & $74.5 \%$ & $75.7 \%$ & $74.2 \%$ \\
\hline Neither agree nor disagree & $19.1 \%$ & $10.5 \%$ & $10.9 \%$ & $13.5 \%$ & $14.5 \%$ \\
\hline Disagree & $9 \%$ & $13.2 \%$ & $14.5 \%$ & $10.8 \%$ & $11.3 \%$ \\
\hline
\end{tabular}

From $85.5 \%$ to $92.1 \%$ of students (on average, $88.7 \%$ ) were satisfied with the results of studying sociological and pedagogical disciplines using CLM. It is a fairly high indicator that could be provoked by the effective organization of m-learning. The average number of learners who were not satisfied with the training outcomes was $5.4 \%$ (from $3.4 \%$ to $10.9 \%$ depending on the university), while the average number of those who expressed an indefinite position comprised $5.9 \%$ (from $2.6 \%$ to $9 \%$ ). In view of this, hypothesis H1 was confirmed. 
From $65.2 \%$ to $76.3 \%$ of respondents (on average, $69.9 \%$ ) agreed that m-learning motivated them to make more efforts to acquire new knowledge and skills. The average number of students who disagreed with this statement was $11.7 \%$ (from $9 \%$ to $15 \%$ depending on the institution), while the average number of those who were not sure with the answer corresponded to $18.3 \%$ (from $13.2 \%$ to $25.8 \%$ ). Thus, hypothesis H2 was affirmed.

From $80 \%$ to $83.1 \%$ of respondents (on average, $82 \%$ ) found the proposed tasks clear and understandable. The average number of students who were difficult to perform the practical assignments was $13.3 \%$ (from $10.5 \%$ to $16.4 \%$ depending on the university). The average number of participants uncertain about the answer was $4.7 \%$ (from $3.4 \%$ to $7.9 \%$ ). Consequently, hypothesis $\mathrm{H} 3$ was verified.

From $69.7 \%$ to $72.7 \%$ of students (on average, $71.1 \%$ ) believed that their communication skills improved owing to the implementation of $\mathrm{m}$-learning. The average number of learners with an opposing view equaled $16 \%$ (from $11.2 \%$ to $20 \%$ depending on the university). Simultaneously, the average number of those who swayed between two opinions was $12.9 \%$ (from $7.3 \%$ to $19.1 \%$ ). In such a manner, hypothesis H4 was proved.

From $63.2 \%$ to $74.5 \%$ of participants (on average, $68 \%$ ) confirmed that their group mates proposed their own ideas concerning the study process and exchanged knowledge. This fact largely characterizes the principle of mutual learning. The average number of students with a contrary opinion constituted $12.9 \%$ (from $12.4 \%$ to $18.4 \%$ ), while about $19.1 \%$ of respondents held an indefinite position (from $9.1 \%$ to $22.5 \%$ ). Given these data, hypothesis H5 was validated.

From $60.5 \%$ to $70.9 \%$ of students (on average, $66.8 \%$ ) required online support to complete their assignments successfully, while $16 \%$ of respondents needed no external assistance (from $14.6 \%$ to $21.1 \%$ depending on the institution). The average number of students in doubt comprised $17.2 \%$ (from $10.9 \%$ to $21.3 \%$ ). Accordingly, hypothesis H6 was affirmed.

From $63.2 \%$ to $70.8 \%$ of the surveyed (on average, $68 \%$ ) confirmed that CLM contributes to the perception of teacher support as a component that improves learning outcomes. The average number of students who disagreed with this statement was $14.1 \%$ (from $11.2 \%$ to $21.8 \%$ ), and the average number of those who neither agreed nor disagreed with this idea amounted to $17.9 \%$ (from $9.1 \%$ to $21.1 \%$ ). Hence, hypothesis $\mathrm{H} 7$ was confirmed.

From $71.9 \%$ to $76.3 \%$ of learners (on average, $74.2 \%$ ) believed that their knowledge was evaluated fairly. It should be remarked that it is an important motivating factor for the majority of students, which is explicitly supported by CML. The average number of surveyed who did not with the fairness of the assessment was $11.3 \%$ (from $9.0 \%$ to $14.5 \%$ ). In parallel, the average number of those who were not sure about the assessment impartiality equaled $14.5 \%$ (from $10.5 \%$ to $19.1 \%$ depending on the university). As a consequence, given the survey data, hypothesis H8 was also deemed valid.

The main result of the experiment was the creation of a CML environment that complemented already existing e-learning methods and LMSs. Teachers and students noted the ease of access to the forum and LMS content and its simple management. 
Besides, both educators and learners underlined the clarity and comprehensibility of the theoretical material and practical tasks. The study findings confirmed the need to implement the principles of communication, cooperation, mutual learning, and coordination of students' actions by the teacher, as components of high quality and effective CML.

Activities performed by students in a mobile environment included: accessing to LMS content, watching YouTube videos, downloading files, messaging on the forum, uploading assignment reports, participating in video conferences, social networking, and creating forms for conducting online surveys. During the experiment, no technical problems when using mobile technologies were noted.

Among the challenges that emerged in the research process, above all, should be noted the diversity of working styles of student groups associated with different levels of knowledge and motivation. Ideally, the distribution of tasks within the group should be performed on an equal and complementary basis. Nevertheless, the current study included groups with a clearly expressed leader and a follower student so that the tasks' distribution was unbalanced. The most critical situation was in groups where an outsider performed no useful functions at all. However, this collision can be attributed to the already common issue of student groups' heterogeneity rather than to m-learning disadvantages.

\section{Discussion}

The findings of this investigation demonstrate the benefits of CML within a clearly defined learning context. Despite this, a considerable body of literature points to a number of difficulties with m-learning methodology. Researchers indicate that many students have only the simplest or outdated smartphones with minimal characteristics. In addition, scholars provide an argument about the lack of m-learning pedagogical skills among lecturers, lack of policies to guide the implementation of m-learning, poor attitudes among students and lecturers, and insufficient learning security [29].

For a comparative analysis of the obtained results, it seems useful to turn to the experience of those developing countries that are just beginning to introduce m-learning technologies into education. Among them are many African countries. Global communications were brought to the African continent a little later, which slowed down the introduction of information and communication technologies. Kaliisa and Picard [30], in their review based on 2010-2016 surveys, have provided a representative sample of data for Botswana, Ghana, Egypt, Kenya, Mozambique, Nigeria, Tanzania, Uganda, and the Republic of South Africa. They have confirmed that, in these countries, smartphones remain the most common devices used in m-learning. Among the advantages of mobile education, the authors mention close collaboration between students and teachers, regular communication, reduced education costs, training flexibility, and support in self-regulated learning.

A retrospective analysis of m-learning development, covering 110 articles [31], confirmed the effectiveness of this approach and its positive impact on the existing education system. The expansion of the number and scope of scientific publications on this matter occurred after 2009. At that time, no more than $15 \%$ of articles were 
devoted to cooperative learning. Since 2009, the main areas of m-learning application (podcasts, gamification, supplementing lectures with visual materials, problemoriented tasks, self-regulated learning, and testing) were not changed significantly.

Authors from developing countries continue to study student satisfaction with mlearning [32]. El-Sofany and El-Haggar have examined students' use of mobile access to various educational and administrative resources as well as technical skills required to apply m-learning technologies among 200 respondents from colleges and universities of Egypt and Saudi Arabia. Researchers indicate that participation in video conferences causes the biggest technical problems for students ( $30 \%$ from the total). In terms of accessibility, the greatest difficulties arise when accessing library services ( $40 \%$ from the total).

The user-friendly nature of m-learning technologies and the associated frequency of use of educational resources by students, educators, and management were studied in Saudi Arabia at King Faisal University [33]. Al Mulhem has outlined that the learners' experience from m-learning is mainly positive. Though, it turned out that the frequency of use of such educational resources depends on the awareness of educators and students about the availability and capabilities of m-learning tools. This awareness is still below $100 \%$.

A growing body of literature generalizes methods and technologies for implementing m-learning [34]. To unify the practices of collaborative, individual, active, and project-oriented learning, Bosman and Fern Haber propose to consider the broader concept of authentic learning when the educational methods and tasks are associated with the student's activity and are aimed at developing the most important competencies for the person [35]. One of the abilities of m-learning is tracking student's behavior in the training environment [36]. The analysis of the achieved m-learning results provides opportunities for detailed customization of individual training trajectories, which can be done using adaptive algorithms based on artificial intelligence and gamification [37]. It is expected that such an adaptive learning approach will be actively developed in the future and will be focused on m-learning techniques [38].

\section{Conclusion}

The experiment on the introduction of m-learning and the formation of a collaborative environment for teaching sociological and education disciplines was carried out in three Russian universities (MSPU, NEFU, UTMN) and one Kazakh university (KNPU). During the study, the involved participants were proposed various mlearning content: links to self-paced YouTube videos, instructions and links for accessing mobile applications for online sociological and educational research (SurveyMonkey and Google Forms), and components of the collaborative learning environment implemented in the LMS (forum, training assignments and a platform for posting, commenting and revising them).

The collaborative mobile environment was based on the principles of communication and cooperation of users, mutual learning, and coordination of learner's actions by the teacher. Testing the effectiveness of these principles created the foundation for 
the respondents' survey and the formation of research hypotheses. An essential feature of CML is the ability for a flexible transition from blended to distance learning models and vice versa.

Analysis of the research results confirmed the validity of eight proposed hypotheses. Thus, it was proved that CML ensures student satisfaction with the educational process and motivates learners to make more efforts to acquire new knowledge and skills. Furthermore, the examination outcomes proved that CML guarantees that students understand the content of the proposed practical lessons, ensures the development of students' communication skills, and promotes mutual learning through the exchange of ideas and knowledge. It was confirmed that regular online support from teachers and fellow students is required for the successful CML application. Besides, it was established that the teacher's coordination of work in the course of CML application contributes to the student's feeling of the educator's involvement and provokes a sense of fairness in knowledge assessment.

The practical significance of the research results lies in the fact that they provide an opportunity for effective implementation of CML technologies as a means of formation of students' competencies.

The scientific novelty of the current research stems from the fact that it analyzes the effectiveness of CML implementation in the formation of students' competencies. Furthermore, the present work presents new experimental data that confirm the positive influence of m-learning.

\section{$7 \quad$ References}

[1] Kumar Basak, S., Wotto, M., Belanger, P. (2018). E-learning, M-learning and D-learning: Conceptual definition and comparative analysis. E-Learning and Digital Media, 15(4): 191-216. https://doi.org/10.1177/2042753018785180

[2] Xie, K., Heddy, B.C., Vongkulluksn, V.W. (2019). Examining engagement in context using experience-sampling method with mobile technology Contemporary Educational Psychology, 59: 101788. https://doi.org/10.1016/j.cedpsych.2019.101788

[3] Hargittai, E. (2020). Potential biases in big data: Omitted voices on social media. Social Science Computer Review, 38(1): 10-24. https://doi.org/10.1177/0894439318 $\underline{788322}$

[4] Brandt, J., Buckingham, K., Buntain, C., Anderson, W., Ray, S., Pool, J.R., Ferrari, N. (2020). Identifying social media user demographics and topic diversity with computational social science: a case study of a major international policy forum. Journal of Computational Social Science, 3: 167-188. https://doi.org/10.1007/s42001-019-00061-9

[5] Marcus, V.B. Atan, N.A., Talib, R. Latif, A.A., S.M. (2019). Promoting Students' Generic Skills with the Integration of e-Service Learning Platform. International Journal of Emerging Technologies in Learning. 14(20): 4-17

[6] Navarro, C.X., Molina, A.I., Redondo, M.A., Juárez-Ramírez, R. (2016). Framework to evaluate m-learning systems: A technological and pedagogical approach. IEEE Revista Iberoamericana de Tecnologias del Aprendizaje, 11(1): 33-40. https://doi.org/10.1109/ $\underline{\text { rita.2016.2518459 }}$ 
[7] Purcell, J.W. (2017). Community-Engaged Pedagogy in the Virtual Classroom: Integrating eService-Learning into Online Leadership Education. Journal of Leadership Studies, 11(1): 65-70. https://doi.org/10.1002/jls.21515

[8] Suartama, I.K., Setyosari, P., Sulthoni, S., Ulfa, S. (2019). Development of an instructional design model for mobile blended learning in higher education. International Journal of Emerging Technologies in Learning, 14(16): 4-22. https://doi.org/10.3991/ijet. v14i16.10633

[9] Garca-Gutierrez, J., Ruiz-Corbella, M., del Pozo Armentia, A. (2017). Developing civic engagement in distance higher education: a case study of virtual service-learning (vSL) Programme in Spain. Open Praxis, 9(2): 235-244. https://doi.org/10.5944/ openpraxis.9.2.578

[10] Pimmer, C., Brühlmann, F., Odetola, T.D., Oluwasola, D.O., Dipeolu, O., Ajuwon, A.J. (2019). Facilitating professional mobile learning communities with instant messaging. Computers \& Education, 128: 102-112. https://doi.org/10.1016/j.compedu. 2018.09.005

[11] Boyle, A.M., O'Sullivan, L.F. (2016). Staying connected: Computer-mediated and face-toface communication in college students' dating relationships. Cyberpsychology, Behavior, and Social Networking, 19(5): 299-307. https://doi.org/10.1089/cyber.2015.0293

[12] Almaiah, M.A., Alismaiel, O.A. (2019). Examination of factors influencing the use of mobile learning system: An empirical study. Education and Information Technologies, 24(1): 885-909. https://doi.org/10.1007/s10639-018-9810-7

[13] Zydney, J.M., Warner, Z. (2016). Mobile apps for science learning: Review of research. Computers \& Education, 94: 1-17. https://doi.org/10.1016/j.compedu.2015. 11.001

[14] Sánchez-Prieto, J.C., Olmos-Migueláñez, S., García-Peñalvo, F.J. (2016). Informal tools in formal contexts: Development of a model to assess the acceptance of mobile technologies among teachers Computers in Human Behavior, 55: 519-528. https://doi.org/10.1016/ j.chb.2015.07.002

[15] Grant, M.M. (2019). Difficulties in defining mobile learning: Analysis, design characteristics, and implications. Educational Technology Research and Development, 67(2): 361388. https://doi.org/10.1007/s11423-018-09641-4

[16] Han, F., Ellis, R.A. (2019). Identifying consistent patterns of quality learning discussions in blended learning. The Internet and Higher Education, 40: 12-19. https://doi.org/10.1016/j.iheduc.2018.09.002

[17] Harris, U.S. (2017). Virtual partnerships: engaging students in e-service learning using computer-mediated communication. Asia Pacific Media Educator, 27(1): 103-117. https://doi.org/10.1177/1326365x17701792

[18] Gašević, D., Joksimović, S., Eagan, B.R., Shaffer, D.W. (2019). SENS: Network analytics to combine social and cognitive perspectives of collaborative learning. Computers in $\mathrm{Hu}-$ man Behavior, 92: 562-577. https://doi.org/10.1016/j.chb.2018.07.003

[19] Heflin, H., Shewmaker, J., \& Nguyen, J. (2017). Impact of mobile technology on student attitudes, engagement, and learning. Computers \& Education, 107, 91-99. https://doi.org/10.1016/j.compedu.2017.01.006

[20] Syakur, A., Musyarofah, L., Sulistiyaningsih, S., Wike, W. (2020). The Effect of Project Based Learning (PjBL) Continuing Learning Innovation on Learning Outcomes of English in Higher Education. Budapest International Research and Critics in Linguistics and Education Journal, 3(1): 625-630. https://doi.org/10.33258/birle.v3i1.860 
[21] Lin, X.F., Deng, C., Hu, Q., Tsai, C.C. (2019). Chinese undergraduate students' perceptions of mobile learning: Conceptions, learning profiles, and approaches. Journal of Computer Assisted Learning, 35(3): 317-333. https://doi.org/10.1111/jcal.12333

[22] Boyarchuk, A., Kharchenko, V., Sklyar, V. (2018). Models and cases for sustainable university-industry cooperation in IT sector. In Proceedings of the IEEE 9th International Conference on Dependable Systems, Services and Technologies (DESSERT'2018), Leeds, UK. pp. 667-671. https://doi.org/10.1109/dessert.2018.8409216

[23] Akhmetshin, E. M., Mueller, J. E., Yumashev, A. V., Kozachek, A. V., Prikhodko, A. N., \& Safonova, E. E. (2019). Acquisition of entrepreneurial skills and competences: Curriculum development and evaluation for higher education. Journal of Entrepreneurship Education, 22(1): 1-12.

[24] Yumashev, A. V., Utyuzh, A. S., Admakin, O. I., Doroshina, V. Y., \& Volchkova, I. R. (2018). Effect of mesodiencephalic stimulation on adaptation to stress and academic performance of students. International Journal of Learning and Change, 10(4): 359-367. https://doi.org/10.1504/ijlc.2018.10016003

[25] Starov, O., Sklyar, V., Kharchenko, V., Boyarchuk, A., Phillips, C. (2014). A student-inthe-middle approach for successful university and business cooperation in IT. In Proceedings of the University-Industry Interaction Conference (UIIN'2014), Barcelona, Spain. pp. 193-207.

[26] Lin, C.-Y., Huang, C.-K., Ko C.-J. (2020). The impact of perceived enjoyment on team effectiveness and individual learning in a blended learning business course: The mediating effect of knowledge sharing. Australasian Journal of Educational Technology, 36(1): 126-141. https://doi.org/10.14742/ajet.4446

[27] Nielsen, D. (2016). Facilitating service learning in the online technical communication classroom. Journal of Technical Writing and Communication, 46(2): 236-256. https://doi.org/10.1177/0047281616633600

[28] Popova, N.G., Biricheva, E.V., Beavitt, T.A. (2018). Three Aspects of the Phenomenon of Science: In Search for Unity among Sociologists. The Education and science journal, 20(9): 35-55. https://doi.org/10.17853/1994-5639-2018-9-35-55

[29] Qureshi, M.I., Khan, N., Gillani, S.M.A.H., Raza, H. (2020). A Systematic Review of Past Decade of Mobile Learning: What we Learned and Where to Go. International Journal of Interactive Mobile Technologies, 14(6): 67-81. https://doi.org/10.3991/ijim.v14i06. $\underline{13479}$

[30] Kaliisa, R., Picard, M. (2017). A systematic review on mobile learning in higher education: The African perspective. The Turkish Online Journal of Educational Technology, 16(1): 1-18.

[31] Sung, Y.T., Chang, K.E., Liu, T.C. (2016). The effects of integrating mobile devices with teaching and learning on students' learning performance: A meta-analysis and research synthesis. Computers \& Education, 94: 252-275. https://doi.org/10.1016/j.compedu. 2015.11.008

[32] El-Sofany, H., El-Haggar, N. (2020). The Effectiveness of Using Mobile Learning Techniques to Improve Learning Outcomes in Higher Education. International Journal of Interactive Mobile Technologies, 14(8): 4-18. https://doi.org/10.3991/ijim.v14i08. $\underline{13125}$

[33] Al Mulhem, A. (2020). Exploring the Key Factors in the Use of an E-Learning System among Students at King Faisal University, Saudi Arabia. International Journal of Interactive Mobile Technologies,14(3): 19-37. https://doi.org/10.3991/ijim.v14i03.11576

[34] Cress, U., Rosé, C. P., Law, N., Ludvigsen, S. (2019). Investigating the complexity of computer-supported collaborative learning in action. International Journal of Computer- 
Supported Collaborative Learning, 14(2): 137-142. https://doi.org/10.1007/s11412-01909305-2

[35] Bosman, L., Fernhaber, S. (2019). Applying authentic learning through cultivation of the entrepreneurial mindset in the engineering classroom. Education Sciences, 9(1): 7. https://doi.org/10.3390/educsci9010007

[36] Lai, S., Sun, B., Wu, F., Xiao, R. (2020). Automatic Personality Identification Using Students' Online Learning Behavior. IEEE Transactions on Learning Technologies, 13(1): 2637. https://doi.org/10.1109/tlt.2019.2924223

[37] Lavoué, É., Monterrat, B., Desmarais, M., George, S. (2019). Adaptive Gamification for Learning Environments. IEEE Transactions on Learning Technologies, 12(1): 16-28. https://doi.org/10.1109/tlt.2018.2823710

[38] Normadhi, N.B.A., Shuib, L., Nasir, H.N.M., Bimba, A., Idris, N., Balakrishnan, V. (2019). Identification of personal traits in adaptive learning environment: Systematic literature review. Computers \& Education, 130: 168-190. https://doi.org/10.1016/j. compedu.2018.11.005

\section{Authors}

Zhampeissova Korlan Kabykenovna is a Doctor of Pedagogical Sciences, Professor of the Department of Pedagogy, Abai Kazakh National Pedagogical University, Almaty, Kazakhstan. Email: zhampeissovako@rambler.ru, khorlan_17@mail.ru

Kosareva Irina Aleksandrovna is a PhD of Engineering Sciences, Associate Professor of the Department of General Theoretical Disciplines, Moscow State Automobile and Road Construction Technical University, Moscow, Russia.

Borisova Uliana Semenovna is a Doctor of Sociological Sciences, Professor of the Department of HR and Sociology, North-Eastern Federal University (NEFU), Yakutsk, Russia.

Article submitted 2020-09-12. Resubmitted 2020-10-26. Final acceptance 2020-10-27. Final version published as submitted by the authors. 